\title{
Establishing Relationship between Cbr Value and Physical Properties of Soil
}

\author{
Naveen B Shirur ${ }^{1}$, Santosh G Hiremath ${ }^{2}$ \\ ${ }^{1}$ (Student, Department of Civil Engineering, BEC Bagalkot, India) \\ 2 (Professor, Department of Civil Engineering, BEC Bagalkot, India)
}

\begin{abstract}
Subgrade strength is mostly affected by thickness of pavement, in Highway design. California Bearing Ratio (CBR) is the one of the method to determine the sub grade strength.CBR test is laborious and time consuming, hence a method is proposed for correlating CBR value with the LL, PL, SL, PI, OMC and $M D D$. In the present study, different soils samples (having $20<L L<70$ ) were collected from different locations. Various laboratory tests including Atterberg limit, Specific Gravity, Gradation Analysis, CBR and compaction were performed on the samples. Various linear relationships between index properties and CBR of the samples were investigated using simple and multiple linear regression analysis and also predictive equation estimating $C B R$ from the experimental index values were developed.
\end{abstract}

Keywords: Coefficient of correlation $(R)^{2}, M L R A$, Regression, Soaked CBR value, SLRA.

\section{Introduction}

All civil engineering works such as the construction of highway, building structure, dam and other structure have a strong relationship with soil. All those structures need a strong layer of soil to make sure the structure are strong and stable. The weakness and failure of soil may capable make the structure which builds above of it become weak and collapse or fail. Therefore, the proper analysis of soil is necessary to ensure that these structures remain safe and free endue settling and collapse. Soil conditions vary from one location to another location. Hence it is difficult to predict the behavior of soil. As a result, soil conditions at every site must be thoroughly investigated for proper design.

Most of the Indian highways system consists of flexible pavement. There are different methods of design of flexible pavement. The California Bearing Ratio (CBR) test is an empirical method of design of flexible pavement. Sub grade soil bearing capacity plays very important role for the design of highway structure. It determines the thickness of the pavement. In other words, sub grade that has lower CBR value will have thicker pavement compared with the sub grade that has higher CBR value. CBR values can be measured directly in the laboratory test in accordance with IS 2720 part-XVI on soil sample obtained from the site.

However, to conduct a CBR test, representative soil sample has to be collected from the location selected, from which a remoulded specimen has to be prepared at predetermined Optimum moisture content and maximum dry density with standard proctor compaction, for the test to be conducted. To obtain soaked CBR value of a soil sample, it takes about a week, making CBR test expensive, time consuming and laborious. As a result, only a limited number of CBR test could be performed per kilometer length of the proposed road to be constructed. Such limited number of CBR test results may not generally reveal the variation in the CBR values over the length of the road to enable rational, economic and safe construction.

This could be avoided only if a large number of soil sample are taken. But such a procedure will increase the project cost and time. . To overcome these difficulties, an attempt has been made in this study to correlate CBR value statistically with the liquid limit (LL), Plastic limit (PL), Plasticity index (PI), maximum dry density (MDD) and optimum moisture content (OMC) of soil, because these tests are simple and can be completed with less period of time.

\section{Experimental Work}

Twenty numbers of disturbed soil samples were collected (having different liquid limit) from different locations from in and around the city of Bagalkot district of Karnataka, India. The selected soil samples were tested for CBR value, optimum moisture content, maximum dry density, particle size distribution, liquid limit, plastic limit, shrinkage limit, plasticity index. All these tests were performed according to IS code specification. In this study, regression models, both simple linear regression analysis (SLRA) and multiple linear regression analysis (MLRA), were developed for estimating soaked CBR value using physical properties of soils. 
Table.1 Results of Laboratory Test for Soil Samples

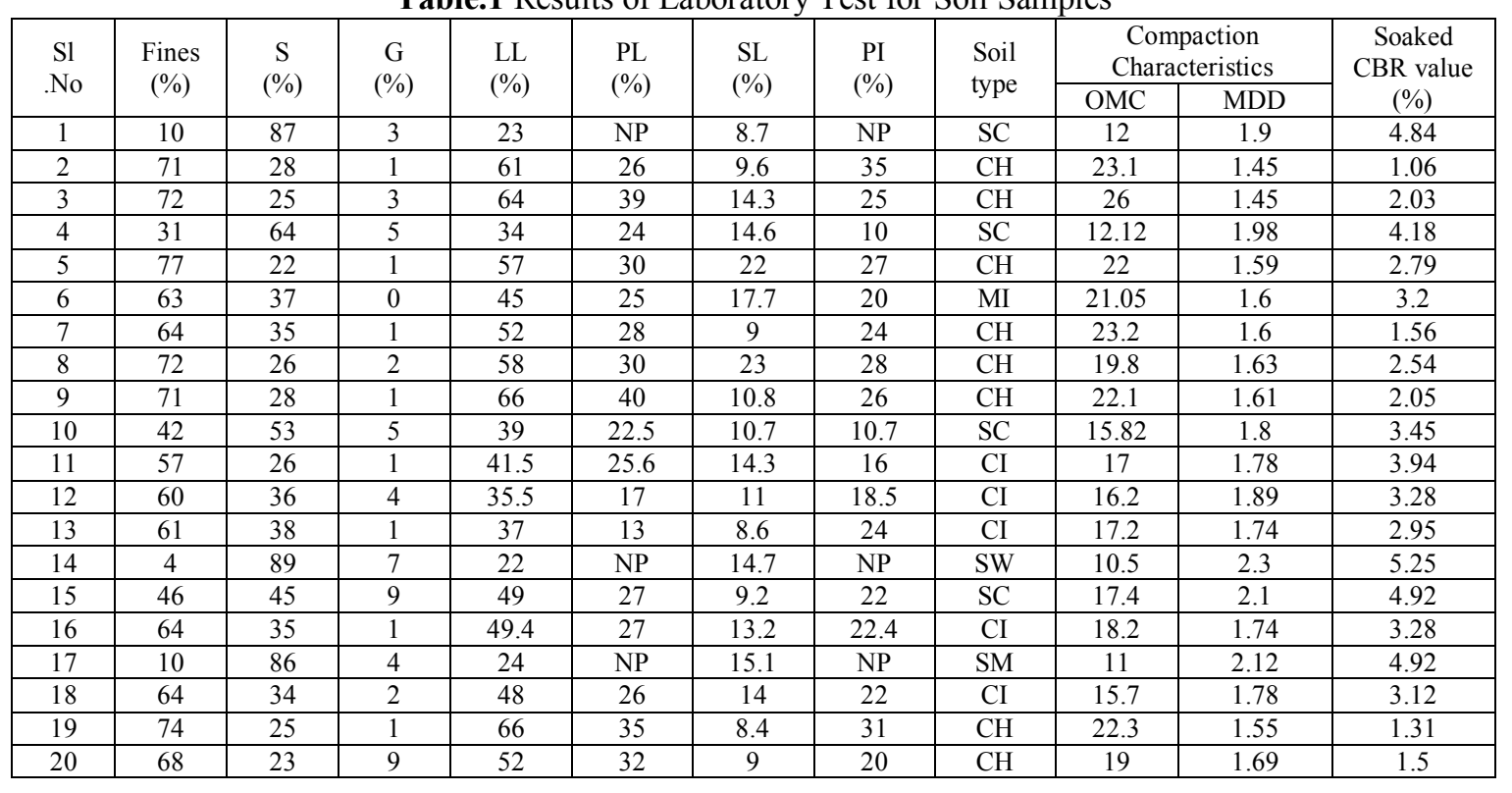

\section{Results And Discussion}

Table 1 gives the results of various soil properties from the experimental conducted in the laboratory for twenty samples taken for present investigation. The properties include index properties of soils such as liquid limit, plastic limit and specific gravity, compaction characteristics such as maximum dry density and optimum moisture content, grain size distribution analysis such as gravel(G\%), sand(S\%), silt and clay, California Bearing Ratio test is conducted at optimum moisture content. The range of soil properties studied in this investigation is: Gravel $=0-17 \%$, Sand $=20-90 \%$, Fines (silt \& clay) $=4-75 \%, \mathrm{LL}=20-66 \%, \mathrm{PL}=20-35 \%$, $\mathrm{MDD}=1.45-2.3 \mathrm{gm} / \mathrm{cc}, \mathrm{OMC}=10-23 \%$ and soaked $\mathrm{CBR}=1-6 \%$. A wide range of soil samples including fine and coarse grained soils are selected to predict soaked CBR value.

\subsection{Regression Analysis}

The various regression analysis between soaked CBR value with respect to different soil properties are presented in Fig. 1, 2, and 3. It shows the linear trend line, which shows the effect of various soil properties with CBR value.

\subsubsection{Simple Linear Regression Analysis (SLRA)}

Simple Linear Regression Analysis (SLRA) was carried out by considering soaked CBR value as dependent variable and liquid limit, plastic limit, plasticity index, shrinkage limit, maximum dry density and optimum moisture content are considered as independent variables. It has been carried out to develop the correlation between individual soil property and soaked CBR value.

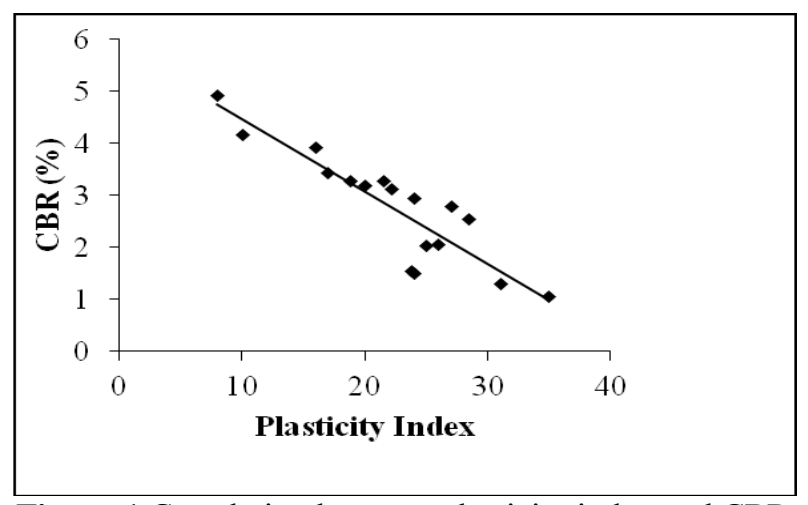

Figure 1 Correlation between plasticity index and CBR

Sample number 1, 14 and 17 are not considered for this regression analysis because these soils are non plastic (NP) in nature therefore using seventeen numbers of samples regression analyses have been made. The coefficient of correlation $\mathrm{R}^{2}$ was found to be 0.72 . Effect of soil properties on CBR value can be explained as 
liquid limit and plastic limit has less influence on CBR value. But CBR value varies with plasticity index such that as plasticity index increases CBR value decreases. This shows that there is a fair to good relationship exists between CBR values for plastic nature of soils only.

From figure 2 it is observed that there is linear relationship exists between maximum dry density and CBR value. As maximum dry density increases CBR values also increases indicating linear relationship exists between these two parameters. From SLRA the coefficient of correlation $\mathrm{R}^{2}$ for these two parameter is found to be 0.78 , it represents good correlation between them.

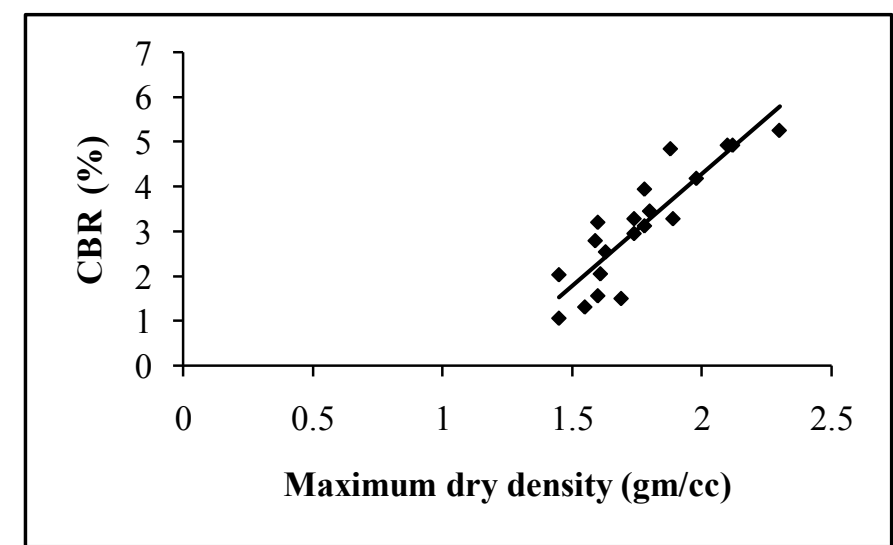

Figure 2 Correlation between maximum dry density and CBR

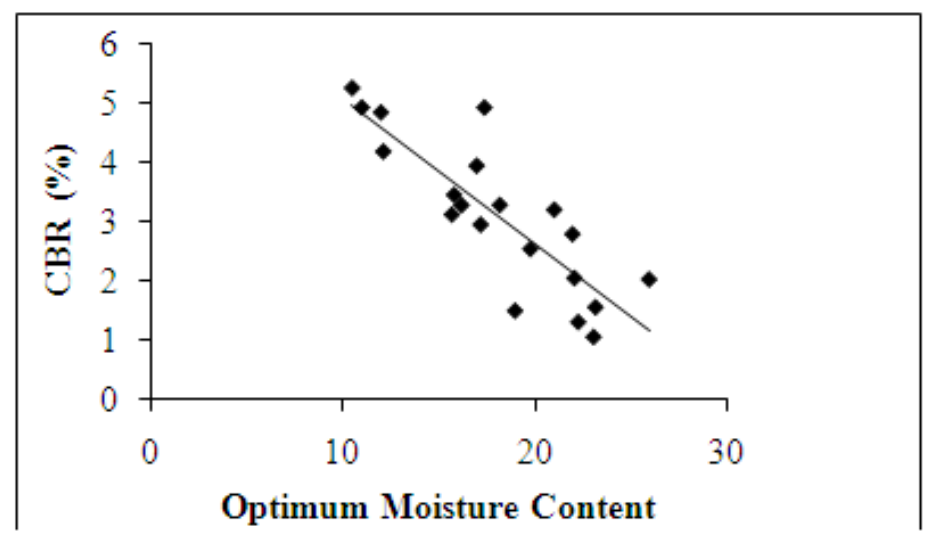

Figure 3 Correlation between Optimum moisture content and CBR

The above figure 3 indicates that as moisture content increases CBR value decreases. The model developed for soaked CBR value has correlation coefficient $\mathrm{R}^{2}=0.70$, indicating a reasonable fit to the data and also it indicates that as optimum moisture content increases $\mathrm{CBR}$ value increases.

\subsubsection{Multiple Linear Regression Analysis (MLRA)}

It has been carried out by considering soaked CBR value as the dependent variable and remaining soil properties as independent variable. It can be expressed as given below:

Soaked CBR $=($ LL, PL, PI, MDD, OMC)

Equations

1. $\mathrm{CBR}=5.09477-0.09323(\mathrm{LL})+0.10939(\mathrm{SL})+0.022566(\mathrm{SI})$

2. $\mathrm{CBR}=5.813-0.007826(\mathrm{LL})+0.12097(\mathrm{PL})$

$3 . \mathrm{CBR}=-4.8353-1.56856(\mathrm{OMC})+4.6351(\mathrm{MDD})$

4. $\mathrm{CBR}=-3.2353-0.06939(\mathrm{PI})+2.8(\mathrm{MDD})$

5. $\mathrm{CBR}=6.5452-0.07703(\mathrm{OMC})-0.10395(\mathrm{PI})$

Where, $\mathrm{CBR}=$ California Bearing Ratio, $\mathrm{LL}=$ Liquid Limit, $\mathrm{PL}=$ Plastic Limit, $\mathrm{SL}=$ Shrinkage Limit, $\mathrm{PI}=$ Plasticity Index, $\mathrm{OMC}=$ Optimum Moisture Content, $\mathrm{MDD}=$ Maximum Dry Density.

Equation 1,2,3,4 and 5 shows the multiple variable regression analysis. These equations include the correlation of all the parameters with CBR value. The three parameters plasticity index, maximum dry density and optimum moisture content directly affects the CBR value. 
Equation 3 shows the correlation between CBR and optimum moisture content and maximum dry density. It is observed from figure 4 that the experimental soaked CBR values are close to predicted values. The model developed for CBR value has correlation coefficient $\left(R^{2}\right)=0.82$ indicating a reasonable fit to all types of soil.

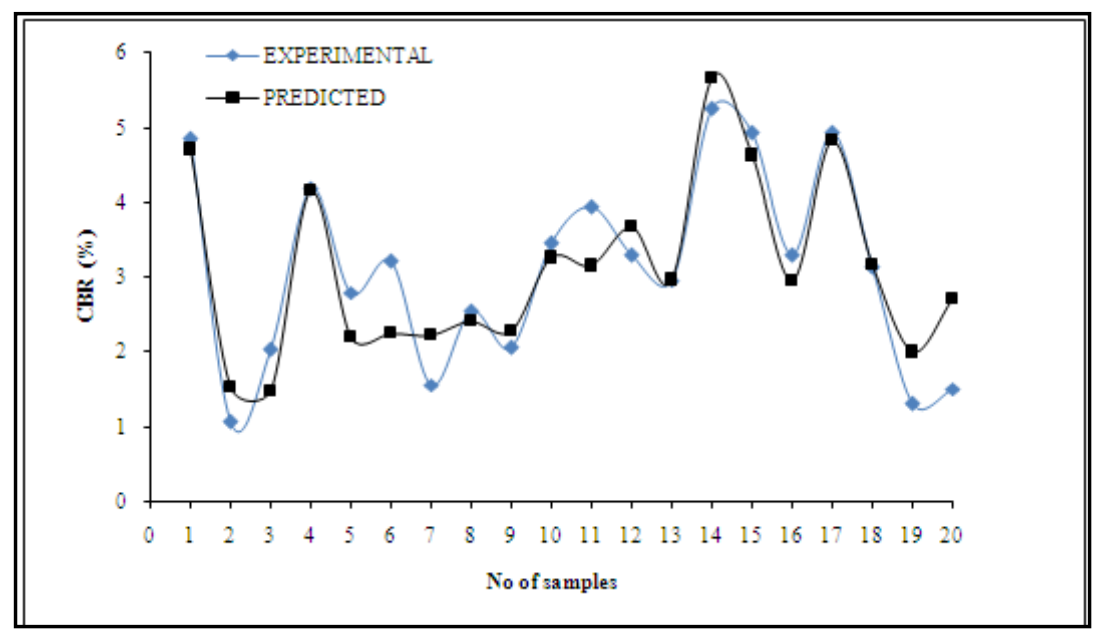

Figure 4.Comparison between experimental and predicted CBR value obtained from equation 3

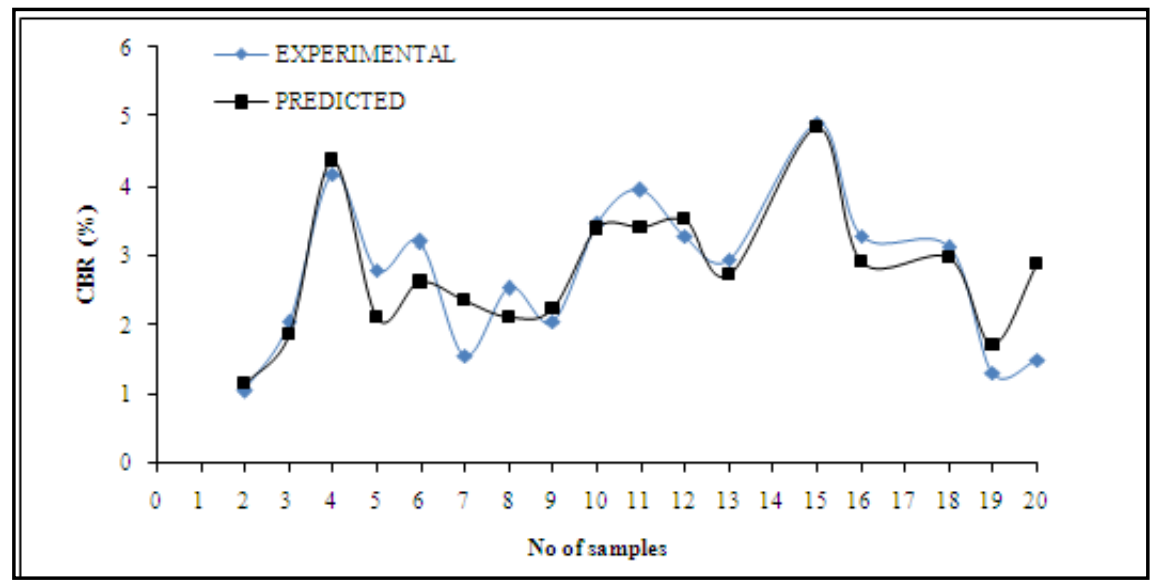

Figure 5.Comparison between experimental and predicted CBR value obtained from equation 4

It is known from simple linear regression analysis (SLRA) that CBR value decreases with increase in plasticity index and also increases with increase in maximum dry density. From SLRA coefficient of correlation $\mathrm{R}^{2}$ for plasticity index and maximum dry density are 0.72 and 0.78 respectively. Hence an attempt is made to correlate CBR from plasticity index and maximum dry density. From the correlation coefficient $\mathrm{R}^{2}=0.76$, it is concluded from figure 5 that CBR value prediction model based on MLRA are quite near to experimental values.

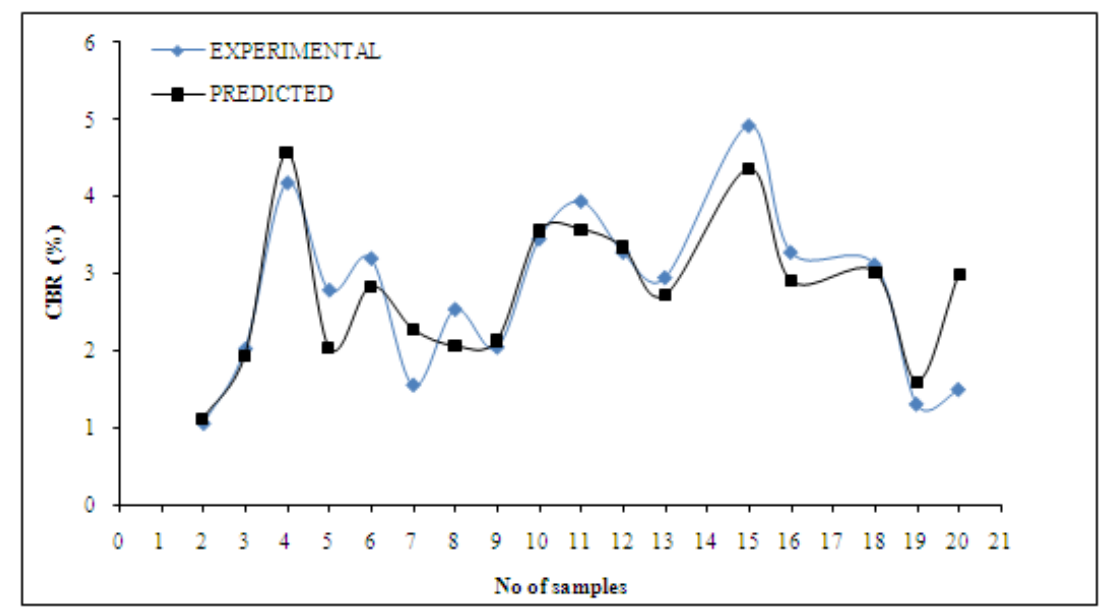

Figure 6.Comparison between experimental and predicted CBR value obtained from equation 5 
The above Figure 6 shows that the effect of moisture content and plasticity index on CBR value of soil samples collected for investigation. It is known from simple linear regression analysis (SLRA) that CBR value decreases with increase in plasticity index and CBR decreases with increase in moisture content. Also coefficient of correlation $\mathrm{R}^{2}$ for optimum moisture content and plasticity index are 0.71 and 0.72 respectively. An attempt is made to correlate CBR value with these two variables using multiple linear regression analysis as shown in equation-5 and $\mathrm{R}^{2}$ value found to be 0.75 . Therefore it is concluded that MLRA holds good for these two parameters.

\section{Conclusion}

[1] Based on experimental results and SLRA, there is no significant relation exists to predict CBR value from liquid limit and plastic limit.

[2] Linear relation exists between plasticity index and CBR value with a coefficient of correlation of $\mathrm{R}^{2}=0.72$.

[3] It is found that good empirical relations $y=4.99 M D D-5.711\left(R^{2}=0.78\right)$ and $y=-0.24430 M C+7.5264$ $\left(\mathrm{R}^{2}=0.71\right)$ obtained by SLRA to predict CBR value from MDD and OMC.

[4] The empirical relation $\mathrm{CBR}=-4.8353-1.56856(\mathrm{OMC})+4.6351(\mathrm{MDD})\left(\mathrm{R}^{2}=0.82\right)$ obtained from multiple linear regression analysis (MLRA) shows good relation to predict CBR value from MDD and OMC.

[5] From the correlation analysis it is clear that, large variation can be observed between experimental and predicted CBR value particularly in case of high compressible clays $(\mathrm{CH})$.

\section{References}

[1] Dilip Kumar Talukdar, A Study of correlation between California Bearing Ratio (CBR) values with other properties of soil. International Journal of Emerging Technology and Advanced Engineering, volume 4 (2014), pp. 559-562.

[2] Soewignjo Agus NUGROHO, Andy HENDRI, and Rahayu NINGSIH, Correlation between Index properties and California Bearing Ratio test of Pekanbaru Soils with and without Soaked. Canadian Journal on Environmental, Construction and Civil Engineering, Vol. 3(2012), No.1, pp. 7-16.

[3] Patel.Rashmi S. and Desai.M.D, CBR Predicted by Index properties for Alluvial soils of South Gujarat. Indian Geotechnical Conference (2010), pp. 79-82.

[4] Ramasubbarao, G.V. and Siva Sankar, G, Predicting Soaked CBR value of fine grained soils using index and compaction characteristics, Jordan Journal of Civil Engineering, volume 7(2013), No.3, pp. 354-360.

[5] B.C. Chattopadhyay and J. Maity, Prediction of CBR of different groups of Alluvial soils for design of flexible pavement. Proceedings of the International Symposium on Engineering under Uncertainty: Safety Assessment and Management (ISEUSAM), pp. 833-847.

[6] J. Danistan and C, Vipulanandan, Relationship between CBR values (un-soaked) and undrained shear strength of artificial CH soils. Centre for Innovative Grouting Material and Technology (2009), pp. 1-2.

[7] Venkatasubramanian. C, Dhinakaran.G, ANN model for predicting CBR from index properties of soils. International journal of civil and structural engineering, Volume 2(2011), No 2. pp, 605-611.

[8] Afeez Adefemi Bello, Regression analysis between properties of subgrade lateritic soil, Department of Civil Engineering, Osun State University, PMB 4494, Osogbo.

[9] Saxena Anil Kumar et.al, Application of Machine Learning Techniques to Predict Soaked CBR Of remoulded soils". International Journal of Engineering Research \& Technology (2013), Vol. 2, Issue 6, pp. 3019-3024.

[10] Dharamveer Singh et.al, Moisture and Compaction based statistical model for estimating CBR of fine grained subgrade soils. International Journal of Earth Sciences and Engineering ISSN 0974-5904, Volume 04(2011), No 06, pp. $100-103$.

[11] Mukesh A. Patel, H. S. Patel, Correlation between physical properties and California Bearing Ratio Test on soils of Gujarat region in Both Soak and Un-soak condition". International Journal of Civil Engineering and Technology, volume 3 (2012), Issue 2, pp. 5059. 